\title{
EFFECTIVE TECHNIQUES IN COST OPTIMIZATION OF CONSTRUCTION PROJECT: AN REVIEW
}

\author{
Anuja Rajguru ${ }^{1}$, Parag Mahatme ${ }^{2}$ \\ ${ }^{1}$ P. G. Scholar, Department of Civil Engineering, PRMCEAM, Badnera, M.S. India \\ ${ }^{2}$ Assistant Professor, Department of Civil Engineering, PRMCEAM, Badnera, M.S. India
}

\begin{abstract}
In the construction project, time and cost are the most important factors to be considered in the planning of every project. The aim of project is to finish the projects on time, within budget and to achieve other project objectives. It is a difficult task undertaken by project managers in practice, which include constantly measuring progress, evaluation of plans, and corrective actions should be taken whenever required. Optimization is a systematic effort made to improve profit margins and obtain the best results under given circumstances. There is a Systematic planning and programming with effective management is necessary for timely completion of the project. there is availability of various tools and techniques for optimization. Optimizing performance of the different techniques adopted at one stage of the construction process may not be beneficial if the methods used are not to up the efficient level. In this approach we have studied various factors which affect the cost of projects. again in this approach we have studied various techniques and various materials used for cost optimization. Also the need of optimization is discussed.
\end{abstract}

Keywords: time, cost, optimization.

\section{INTRODUCTION}

India is the developing country and in the economy of country construction projects and industries play an vital role. Time and cost are two main concerns in a construction and they are used for planning a project. This has increased the importance of time and Cost optimization in construction projects. is necessary to estimate the cost and time of each activity through which the whole duration and total cost of the project are determined to complete the planning task. Optimization is a systematic effort made to improve profit margins and obtain the best results under given circumstances or situations. "Cost Optimization can be defined as the achievement of real and permanent reduction in the unit cost of services provided without damaging their suitability for the in planned use". There is availability of various techniques for optimization and project control software, still many construction projects do not achieve their cost and time objectives. Optimizing performance of the different techniques adopted at one stage of the construction process may not be beneficial if the methods used are not to up the efficient level. Hence it is required to follow and implement the techniques in every stage of the construction process with the analyses of the information available. The methodology and the type of the used in a construction is also plays very important role for the successful completion of a project.

\subsection{Need of Optimization}

The optimization of time and cost is necessary as it could minimize both the time and total cost of project. This optimization in time and cost helps to achieve the greatest benefit.

\section{LITERATURE REVIEW}

Shanmugapriya S., Dr. Subramanian K. (October 2013) [1] Time overruns and Cost overruns has been a major issue in many Indian construction projects. The objective of this paper to study significant factors causing Time overruns and Cost overruns in Indian construction projects. The result accomplished from the survey revealed that the major cause for time overruns are contract modification, material market rate, and high level of quality requirement and the major cause for cost overruns are, change in material specification, high transportation cost, and escalation of materials price.

Salunkhe. A, Patil R (Janeuary2014) [2] Construction delay is considered to be one of the recurring problems in the construction industry and it has an adverse effect on project success in terms of time, cost and quality. The time and cost for performance of a project are usually important to the employer and contractor. The authors highlights the types of construction delays due to which project suffer time and cost overrun. also give external and internal factors that influence the construction process and outlines the effect of delay in large construction projects.

T.Subramani , P S Sruthi, M.Kavitha (June. 2014) [3] The main objectives of this paper are to identify and analyze the causes of cost overrun in construction. The results carried out from survey showed that, poor contract management, slow decision making, poor schedule management, increase in material/machine prices poor design/ delay in providing design, rework due to wrong work, long period between design and time of bidding/tendering and wrong estimation/ estimation method are the major causes of cost overrun. 
Memon A.H, Rahman I.A, Mohd Razaki Abdullah3, Ade Asmi Abdu Azis, (December 2010) [4] Project cost is one of the most important criteria of success of project. the authors are focusing on identification of significant causes affecting construction cost in MARA large projects. From the study author found that contractor's poor site management and supervision, cash flow and financial difficulties faced by contractors, shortage of site workers, inadequate contractor experience, incorrect planning and scheduling by contractors are most severe factors which affect cost of project. while changes in scope of project and frequent design changes are least affecting factors on construction cost.

Benviolent Chigara,Tirivavi Moyo, Fungai Mudzengerere (2013) [5] they made the research for the cost management strategies employed by contractor on building projects. Also made investigation that contractor has to manage project cost. For data collection they made the survey and interviews in Zimbabwe. From study they found that contractor efforts to manage the project cost by concentrating on the management on the project resources. Also the cost management process in Zimbabwe compare to other developing countries is still dominated by prematurely developed automated system or traditional paper based systems of managing project cost information. The author provide a base line information on strategies used for managing project cost.

Barbole A.N., Yuvraj D. Nalwade, Santosh D. Parakh ( June. 2013) [6] The survival today for any company is how to manage its service Cost, quality, and performance. Now a days the customers are continuously demanding high quality and better performance of services and at the same time they want the prices to fall. For this author focus on impact of cost control and cost reduction techniques in present scenario. An objective of this paper is to understand the basic concept of Cost, Cost Control, and Cost Reduction and to study various Tool and Techniques available for Cost Control and Cost Reduction. The Cost Control and Cost Reduction techniques used in manufacturing sector like Value Engineering, Quality Control, and Budgetary Control are specified by the author also cost, cost reduction, cost control etc. Various terms are specified by the author.

C.I. Anyanwu (December 2013) [7] author discuss about the various parameters regarding the cost such as budgeting, cost monitoring and control systems. he discuss about the cost control and the cost control parameter in material, labor, equipments etc .As per the author concept of budget can be define as the translation of an organizational plan into concrete form by way of resource allocation in form of cash. He discuss about the various tools used by the management and cost supervisors for planning, controlling, and monitoring of project such as Gantt chart, network analysis, CPM, PERT. Main focus of author is to study the manufacturing philosophy and inputs which contributes in evaluating and maintaining construction cost in order to reduce the project abandonment which is caused due to cost overrun.
Akintola Omigbodun (June 2001) [8] as per the author value engineering can be defined as the "Engineering is the conceptualization, design, construction, and administration of projects and products whatever the field or application, the engineer solves problems with imagination, creativity and synthesis of various sources of knowledge." To obtain the optimal solution for any engineering design 4 methods has discussed are as follows design for manufacturing and assembly, concurrent engineering, total quality management, and value engineering. A summary of other methods of optimal design methods are compared with value engineering. Cost minimization in building construction is discussed with examples on building projects in West Africa and the Middle East. From study author concluded that, due to application of value engineering to building projects management team obtains a solution which emphasis the functions of project which helps to team to make final choice and which results in cost effective design for project. Value engineering is effective because its procedures give opportunities for raising design issues associated with the latter group of factors as well as design.

Georgekutty C.K, Dr. George Mathew (August - 2012) [9] the innovation of new technology in the construction field is not being adopted in project implementation. this results the growth of construction industry is slow. The real problem is construction will not complete within the budgeted cost and time and finally leads to project failure as end result. Material has a dominating role in construction. If the material has controlled properly then the total project cost would be reduced. To achieve this objective, a research methodology has developed by author to control the material procurement and carrying cost. The methodology adopted which adopted has been validated by a computer program and same is found correct and useful for analysis and controlling any type of projects.

J Zhou, Ped Love, X Wang, Kl Teo And Z (Irani 2013) [10] main objective of the paper is to Optimize construction scheduling. for this author adopted various methods like Mathematical Method, Heuristic Method, Metaheuristic Method. As per the author the Methods and algorithms applied for optimizing construction scheduling efficient and effective.

Khyomesh V. Patel, Prof. Chetna M. Vyas ( May 2011) [11] as per the author to manage the productivity and the cost efficiency material management is more essential. the main objective of the material management are buying or purchasing, storing and inventory control, quality assurance. to achieve these objectives there is need of material management. Author carried out as survey in Ahmadabad to check material management. they investigate that material and equipment contribute $70 \%$ that of total cost. hence for the improvement of product and cost efficiency material management is important. Also proper tracking, controlling is required, if there is poor management may lead to delay of project. 
Hisham Said, Khaled El-Rayes, (June 2011) [12]the authors suggested new model of construction logistics planning to enable the optimization and integration of critical planning decisions of material procurement and also of the material storage on construction site. To check the capability of CLP model one example was analyzed. After the analysis the results obtained that material procurement decisions are affected by the criticality of construction activities consuming the material, site space available, material procurement and site layout constrains.

Andrew N Baldwin, Simon A Austin, Chi-Sun Poon, Li-Yin Shen, Irene Wong (June 2007) [13] the design of high rise building I different from the different of residential and other forms of buildings because of the repetition of the construction and time for the completion of each floor. The main objective of the authors is to develop the model or tools and techniques for analyzing the information for the high rise building. Also, to investigate the difference in the various models for the private residential buildings. Authors discuss about the optimization techniques such as design structural matrix. From study author conclude that there is need to develop the new tools and techniques which can help to designer to analyze the information and to make the improvement in the design management which helps for optimization.

P. Tiwari, K. Parikh, J. Parikh (September 1999) [14] authors discussed about the theoretical basic of hope model. Propose new model of multi criteria optimization technique for buildings. Also Suggested that multi criteria optimization model can $b$ developed to solve the problem in Road, Bridge, and Tunnel construction.

Kale R, Gore G. N, Salunke J. P, (January 2014) [15] Main objective of this paper is cost optimization of bridge including the material. As per the authors the optimization is made for the different grade of steel and concrete. for this they applied direct design method for analyzing the structure. The methodology adopted by them is Nonlinear Programming Problem (NLPP) By Using MATLAB Software with SUMT (Sequential Unconstrained minimization technique). Authors found that there is a significant savings in cost overrun.

C. Sarma, Hoijat Adeli (1998) [16] the objective of this paper is to optimize cost of concrete structures involves beams, slabs, columns, bridges, water tanks, frame structures, tensile members, folded plates, and shear walls, pipes. One method for Cost Optimization Using Reliability Theory is explained. From the study the authors concluded that there is a need to perform research on cost optimization of realistic three-dimensional structures, especially for the large structures with number of members where optimization can result in substantial savings.

Gopal M. Naik , M. Kumar (September 2013) [17] The main objective of the paper is To increase the productivity and necessary to forecast the costs arriving from resources so that the total cost of project can be reduced. The Artificial
Neural Networks have become well established as viable, multipurpose, robust computational methodologies with solid theoretic support and with strong potential to be effective in any discipline, especially in construction. From survey results comes out that the Neural Networks approach has optimized the total project cost by $3.91 \%$, and the duration of the project has been reduced around $5 \%$ of the total duration of the project.

Shrivastava R, Singh S. , Dubey C. G. (2012) [18] Time and cost are the most important factors to be considered in every construction project. Ant colony optimization technique was introduced in the early 1990's as a novel technique for solving hard combinational optimization problem. on basis of that author developed new multi-colony ant algorithm for the optimization of three objectives time-cost quality with quantity. The model is also applied to two objectives time cost trade off problem. The results which are coming out compared to those of the existing approaches. As per the authors Model is capable of compromising between important aspect of construction projects

Seyed Ali Mousavi Dehmourdi (2014) [19] the Objective of this paper are to apply the principles of engineering economics, basic economic concepts, finance and quantitative techniques to modeling and analysis of civil engineering projects. Also a practical application of linear programming in a real life project problem with two objectives as optimization of transporting cost of equipment and finding the best solution for reducing the functional costs of the equipment. Mainly structured linear programming model is used for optimizing the transporting cost of equipment. Applications of this approach helps in determining the need for the replacement and the maintenance analysis are based on the econometric approach to the realistic problems and the result shows that optimization with advanced techniques really helps in minimization of cost of project.

Daisy X.M. Zheng, S. Thomas Ng , Mohan M. Kumaraswamy (September 2002) [20] Completing a construction project with the least time and cost is critical Factor and usually requires the engagement of additional labor and plant or the adoption of alternative construction techniques which add extra cost liabilities to the contractor. For time-cost optimization several analytical models have been developed. From those the Genetic Algorithms (GA) could be used to establish the fitness of solutions by evaluating the objective function and its constraints. the objective of paper is to compare the analytical power of the GA with other techniques proposed for TCO. The results come out which indicate that the GA techniques could generate the most optimal outcome for construction TimeCost Optimization it is more beneficial when the project is large and/or complex.

S. Thomas Ng And Yanshuai Zhang (September 2008) [21] main objective of the paper is to Optimize Construction Time and Cost of project. For this they adopted the Ant Colony Method of optimization. Main aspect is Time, Cost 
And Quality Optimization. They made the Comparison with the other optimization methods. Ant colony method is the multi objective optimization techinque.

Daisy X.M. Zheng, S. Thomas Ng, Mohan M. Kumaraswamy (2002) [22] They applied a Genetic Algorithm to the project for Multi objective optimization. As per the author Genetic Algorithm is multi objective i.e. Time, Cost and Quality optimization. Also GA techniques could generate the most optimal outcome For construction Time cost Optimization.

A.S. Ali, S.N. Kamaruzzaman (2010) [23] as per the author for management of construction 4 parameters important are as follows: scope, cost, time, and quality. the main aim of the author is to find out the problem or parameters which contribute for the cost overrun. for this they carried out the quaternary survey on the live projects. for the data analysis the method used is quantitative based i.e. descriptive statistics and ranking analysis is used. from the investigation they found that factors which contributes to cost overrun was inaccurate or poor estimation of original cost and factor which don't affect is mistake in design for this to control the construction cost method suggested by the author is proper costing and financing. also they concluded that cost overrun is most serious problem which may affect the construction project effectively.

Ming Li ,Guangdong Wurobust, (2014) [24] the objective of this paper is to optimization of a time-cost tradeoff problem. Based on multi objective robust optimization method, a optimization model for time-cost tradeoff problem is developed. The results come out that, by means of adjusting the time and cost robust coefficients, the robust Pareto sets for time-cost tradeoff can be obtained according to different acceptable risk level, from which the decision maker could choose the preferred construction alternative.

Pathak.U.J, Chavan.C.S, Rathode.L.V, Nachare.V.L, Suryawanshi.A.B, (Apr 2014) [25] Low cost housing technologies aim to cut down construction cost by using alternatives to conventional methods and Input. Authors examined the cost effectiveness of using low cost housing technologies in comparison with the traditional construction methods. From Two case studies in India found that about 22 to $26 \%$ of the construction cost including material and labor cost can be saved by using the low cost housing technologies in comparison with traditional construction methods for walling and roofing respectively.

Tam W. Y, (2011) [26] It is necessary to adopt cost effective, innovative and Eco-friendly housing technologies for the construction of houses and buildings for enabling the common people to construct houses at affordable cost. Methodology used by author is to compares construction cost for the traditional and low cost housing technologies. For which Case studies in India are used for the investigation. Construction methods, Strength and durability of the structure, stability, safety of various members are compared during cost reduction. The result found that about
$26.11 \%$ and $22.68 \%$ of the construction cost can be saved by using low cost housing technologies in comparison with the traditional construction methods. This proves that using low cost housing technologies is a cost effective construction approach for the industry.

Nilanjan Sengupta (January 2008) [27] as per the author the cost effective construction technologies are useful and beneficial from both in terms of cost and environment. Author discuss about the some effective technologies in India with their features and advantages. Technologies used in India are

1) Rat trap bond wall: due to this bond cost and material is saved and strength is more 2) Brick arch: it is given with its construction. It is beneficial from appearance point of view

3) Filler slab : its slab construction is also discussed. Its advantageous from economy, appearance, strength, material usage and reduction, less weight, material saving point of view.

4) compressed earth block : it is beneficial because it absorb less water in rainfall.

From the study author concluded that, if we pay attention towards the terms like sanitization of people, manpower development, material devolvement, technical guidance's then the cost effective techniques will be extensively used in the light of sustainable development and protection of environment.

R. Taur, V. Devi (Oct 2009) [28]the main objective of this paper is to point out the various aspect of prefabricated building methodology for low housing. For this different prefabrication techniques with their advantage and importance are given by authors. In a building the foundation, walls, doors and windows, floors, roofs are the most important components which can be analyzed individually based on the needs. There is need for improving the speed of construction and reducing the construction cost. The methods of construction systems suggested by authors are as follows prefabricated roofing components like precast RC planks, structural block walls, precast hollow concrete panels, precast concrete/Ferro cement panels, mortar less block walls.

\section{CONCLUSION}

In this paper we have reviewed different techniques for optimization. To minimize the construction cost and duration at each phase is important. It is a need to meet the present day requirements and to complete the project within the estimated time, cost, and available resources. Mainly affecting the factor on cost of project is delay in project and material. Several methods have been developed and applied to analyze the time-cost problems, but they can optimize only one parameter. Various low cost material also suggested for optimizing the cost of project along with maintaining the quality and strength of the project. Also various mathematical method and software based models studied for optimization. 


\section{REFERENCES}

[1]. Shanmugapriya S., Dr. Subramanian K.,(October 2013) "Investigation of Significant Factors Influencing Time And Cost" International Journal Of Emerging Technology And Advanced Engineering Volume 3.

[2]. Salunkhe. A, Patil R., (Jan-2014) "Effect of Construction Delays on Project Time Overrun: Indian Scenario" Ijret: International Journal of Research in Engineering and Technology volume: 03

[3]. T.Subramani , P S Sruthi, M.Kavitha, (June. 2014) "Causes Of Cost Overrun In Construction" Iosr Journal Of Engineering, vol. 04

[4]. Memon A.H, Rahman I.A, Mohd Razaki Abdullah3, Ade Asmi Abdu Azis, (December 2010) "Factors Affecting Construction Cost In Mara Large Construction Project: Perspective Of Project Management Consultant" International Journal of Sustainable Construction Engineering \& Technology Vol 1, No 2.

[5]. Benviolent Chigara,Tirivavi Moyo, Fungai Mudzengerere (2013) "An Analysis Of Cost Management Strategies Employed By Building Contractors On Project In Zimbabwe" International Journal Of Sustainable Construction Engineering \& Technology Vol 4, No 2.

[6]. Barbole A.N., Y. D. Nalwade, S. D. Parakh (June. 2013) "Impact Of Cost Control And Cost Reduction Techniques On Manufacturing Sector" Indian Streams Research Journal Volume 3.

[7]. C.I. Anyanwu (December 2013) "Project Cost Control in The Nigerian Construction Industry" International Journal Of Engineering Science Invention Volume 2 Issue 12.

[8]. Akintola Omigbodun (June 2001) "Value Engineering and Optimal Building Projects" Journal of Architectural Engineering.

[9]. Georgekutty C.K, Dr.George Mathew (August - 2012)

"Research Methodology For Material Optimization In Construction Projects" International Journal Of Engineering Research \& Technology (Ijert) Vol. 1.

[10]. J Zhou, Ped Love, X Wang, Kl Teo And Z Irani 2013 A Review Of Methods And Algorithms For Optimizing Construction Scheduling" Journal Of The Operational Research Society Vol. 64, No. 8

[11]. Khyomesh V. Patel, Prof. Chetna M. Vyas (13-14 May 2011) "Construction Materials Management On Project Sites" National Conference On Recent Trends In Engineering \& Technology B.V.M. Engineering College, V.V.Nagar, Gujarat, India.

[12]. Hisham Said, Khaled El-Rayes, (June 2011) "Optimizing Material Procurement and Storage on Construction Sites" Journal of Construction Engineering and Management

[13]. Andrew N Baldwin, Simon A Austin and Chi-sun Poon, Li-yin Shen and Irene Wong (June 2007) "Reducing Waste in High-Rise Residential Buildings by Information Modeling at the Design Stage" Surveying and Built Environment Vol 18.

[14]. P. Tiwari, K. Parikh, J. Parikh (September 1999) "Structural Design Considerations In House Builders' Model: Optimization Approach" Journal of Infrastructure Systems.
[15]. Kale R, Gore G. N, Salunke J. P, (January 2014) “Cost Optimization of R.C.C. T-Beam Girder" International Journal Of Soft Computing And Engineering, Volume-3.

[16]. K. C. Sarma, Hoijat Adeli (May 1998) "Cost Optimization Of Concrete Structures" Journal Of Structural Engineering.

[17]. G. M. Naik , M. Kumar, (September 2013) "Project Cost And Duration Optimization Using Soft Computing Techniques" Journal Of Advanced Management Science Vol. 1, No. 3.

[18]. Shrivastava R, Singh S., Dubey C. G. (2012) "Multi Objective Optimization Of Time Cost Quality Quantity Using Multi Colony Ant Algorithm” Int. J. Contemp. Math. Sciences, Vol. 7.

[19]. Seyed Ali Mousavi Dehmourdi (2014) "Optimization Of Construction Cost Applying Advanced Techniques" International Journal Of Structural \& Civil Engineering Research.

[20]. Daisy X.M. Zheng, S. Thomas Ng , M. M. Kumaraswamy (September 2002) "Applying Genetic Algorithm Techniques For Time-Cost Optimization" In: Greenwood, D (Ed.), 18th Annual Arcom Conference, University Of Northumbria. Association Of Researchers In Construction Management, Vol. 2

[21]. S. Thomas Ng And Yanshuai Zhang (September 2008) "Optimizing Construction Time And Cost Using Ant Colony Optimization Approach" Journal Of Construction Engineering And Management (C) ASCE

[22]. Daisy X.M. Zheng, S. Thomas Ng , Mohan M. Kumaraswamy (APRIL 2004) "Applying a Genetic Algorithm-Based Multi objective Approach for Time-Cost Optimization" Journal Of Construction Engineering And Management (C) ASCE

[23]. A.S. Ali, S.N. Kamaruzzaman (2010) "Cost Performance For Building Construction Projects In Klang Valley " Journal Of Building Performance Issn: 2180-2106 Volume 1.

[24]. Ming Li ,Guangdong Wu (2014) "Robust Optimization For Time-Cost Tradeoff Problem In Construction Project" Hindawi Publishing Corporation Abstract and Applied Analysis Volume 2014.

[25]. Pathak.U.J, Chavan.C.S, Rathode.L.V, Nachare.V.L, Suryawanshi.A.B, (Apr 2014) "Cost Effective House By Using Various Construction Techniques And Materials" Indian Journal Of Applied Research Volume: 4.

[26]. Tam W. Y, (2011) "Cost Effectiveness Of Using Low Cost Housing Technologies In Construction" Science Direct.

[27]. Nilanjan Sengupta (January 2008) "Use Of CostEffective Construction Technologies In India To Mitigate Climate Change" Current Science, Vol. 94

[28]. R. Taur, V. Devi (Oct 2009) "Low Cost Housing" ACSGE, BITS Pilani, India 


\section{BIOGRAPHIES}

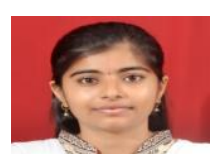

Miss. Anuja M. Rajguru received B.E (Civil Engineering) from SGB Amravati University in 2013 and pursuing M.E. (Construction Engineering and Management) from SGB University. Right now working as a lecturer in the Dept. of Civil Engineering at Prof. Ram Meghe College of Engineering \& Management, Badnera -Amravati

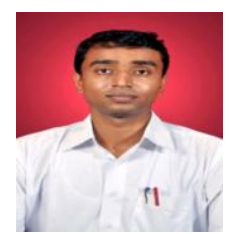

Mr. Parag Mahatme received B.E. (Civil Engineering) \& M.Tech. (Environmental Engineering) from Govt. College of Engineering Amravati in 2009 \& 2011 respectively. He is working as Assistant Professor in PRMCEAM, Badnera. 